\title{
Antigen-bearing dendritic cells from the sublingual mucosa recirculate to distant systemic lymphoid organs to prime mucosal CD8 T cells
}

\author{
$\mathrm{C}$ Hervouet $^{1,2,3}, \mathrm{CLuci}^{1,2,3}, \mathrm{~S}$ Bekri $^{1,2,3}$, T Juhel $^{1,2}, \mathrm{~F} \mathrm{Bihl}^{2,3}, \mathrm{VM}$ Braud $^{2,3}, \mathrm{C} \mathrm{Czerkinsky}^{4}$ and F Anjuère $^{1,2,3}$
}

Effector T cells are described to be primed in the lymph nodes draining the site of immunization and to recirculate to effector sites. Sublingual immunization generates effector T cells able to disseminate to the genital tract. Herein, we report an alternative mechanism that involves the recirculation of antigen-bearing dendritic cells (DCs) in remote lymphoid organs to prime T cells. Sublingual immunization with a muco-adhesive model antigen unable to diffuse through lymphatic or blood vessels induced genital CD8 T cells. The sublingual draining lymph nodes were not mandatory to generate these lymphocytes, and antigen-bearing DCs from distant lymph nodes and spleen were able to prime specific CD8 T cells in a time- and dose-dependent manner. This study demonstrates, for the first time, that antigen-bearing DCs originating from the site of immunization recirculate to distant lymphoid organs and provides insights into the mechanism of distant CD8 T-cell generation by sublingual immunization.

\section{INTRODUCTION}

The female genital mucosa constitutes the major port of entry of sexually transmitted infections. Long-lasting protective immunity at mucosal surfaces involve local B- and T-cell effector cells as well as local memory cells. ${ }^{1,2}$ The generation of genital immunity is better achieved by mucosal immunization rather than by parenteral immunization. ${ }^{3-5}$ The potential of the sublingual route for delivering vaccines has gained interest, because it favors the induction of broadly disseminated mucosal and systemic immune responses. ${ }^{6,7}$ Sublingual immunization was shown efficient to generate immunoglobulin A (IgA) and IgG antibodies and cytotoxic T cells in the female genital tract contrary to parenteral immunization. ${ }^{8,9}$ Furthermore, the sublingual immunization reduces the risk that antigens are redirected to the olfactory bulb as observed after intranasal vaccination. This route of immunization may represent an alternative route to intranasal immunization for human vaccination against urogenital infections. Nevertheless, the inductive mechanisms involved in the generation of genital immunity after sublingual immunization are largely unexplored.
Effective adaptative immunity requires that antigenpresenting cells (APC) process antigens and present epitopes to T cells. Dendritic cells (DCs) are able to prime both CD4 and CD8 T cells. Antigen-bearing DCs are described to carry antigens to the draining lymph nodes where they prime naive CD4 and CD8 T cells. ${ }^{10-12}$ Tissue-derived DC subsets are also known to influence the homing of effector B and T cells to a mucosal site. This has been well described in the gastrointestinal tract where intestinal DCs induced the expression of the alpha4beta7 integrin and the CCR9 (C-C motif chemokine receptor 9) chemokine on activated $\mathrm{B}$ and $\mathrm{T}$ cells, thus favoring their homing to gut-associated lymphoid tissue. ${ }^{13}$ The role of specific DC subsets in the dissemination and maintenance of effector $\mathrm{B}$ and $\mathrm{T}$ cells in the reproductive tract after mucosal immunization remains to be established.

We have recently shown that the sublingual application of an antigen with the mucosal adjuvant Cholera toxin (CT) induces antigen-specific IgA antibody-secreting cells and cytotoxic CD8 T cells that migrate to the female genital tract. ${ }^{89}$ Here, we used the ovalbumin antigen conjugated to the Cholera toxin $\mathrm{B}$ subunit (hereafter called CTBOVA) described to favor the ${ }^{1}$ INSERM, UMR 634, Faculté de Médecine Pasteur, Nice, France. ${ }^{2}$ University of Nice-Sophia Antipolis, Nice, France. ${ }^{3}$ CNRS, CNRS/UNSA UMR7275, Institut de
Pharmacologie Moléculaire et Cellulaire, Valbonne, France and ${ }^{4}$ International Vaccine Institute, Seoul, Korea. Correspondence: F Anjuere (anjuere@unice.fr)

Received 11 August 2012; accepted 28 May 2013; published online 26 June 2013; doi:10.1038/mi.2013.45 
retention of antigens in mucosal tissues through GM1 binding and their efficient delivery in the major histocompatibility complex (MHC) class I pathway. ${ }^{9,10}$ We evaluated the site(s) of priming of OVA-specific CD8 T cells (OT-I CD8 T cells) after sublingual immunization and the nature and distribution of the DCs involved in these responses. Our data demonstrate that the submandibular lymph nodes (SMLN) are not mandatory for the generation of cytotoxic CD8 T-cell responses that disseminate to the genital mucosa and that antigen-bearing DCs originating from the sublingual mucosa recirculate to distant lymphoid organs to activate antigen-specific CD8 T cells.

\section{RESULTS}

\section{Sublingual DC subsets cross-prime CD8 T cells}

The sublingual mucosa is a potent site for inducing mucosal antibody and CD8 $\mathrm{T}$ cells that disseminate to the female genital mucosa, ${ }^{8,9}$ but little attention has been paid to the inductive mechanisms. The sublingual mucosa is lined by a pluristratified epithelium containing $\mathrm{CD}_{4}{ }^{+}$and $\mathrm{MHCII}^{+}$leukocytes (Figure 1a,b, and Cuburu et al. ${ }^{14}$ ). Phenotypical analysis of cells from the sublingual mucosa revealed the presence of $\mathrm{CD}_{11 \mathrm{c}^{+}} \mathrm{MHCII}^{+}$DCs accounting for $1 \%$ of total cells and for $36 \%$ of $\mathrm{CD} 45^{+}$leukocytes. Forty percent of sublingual DCs
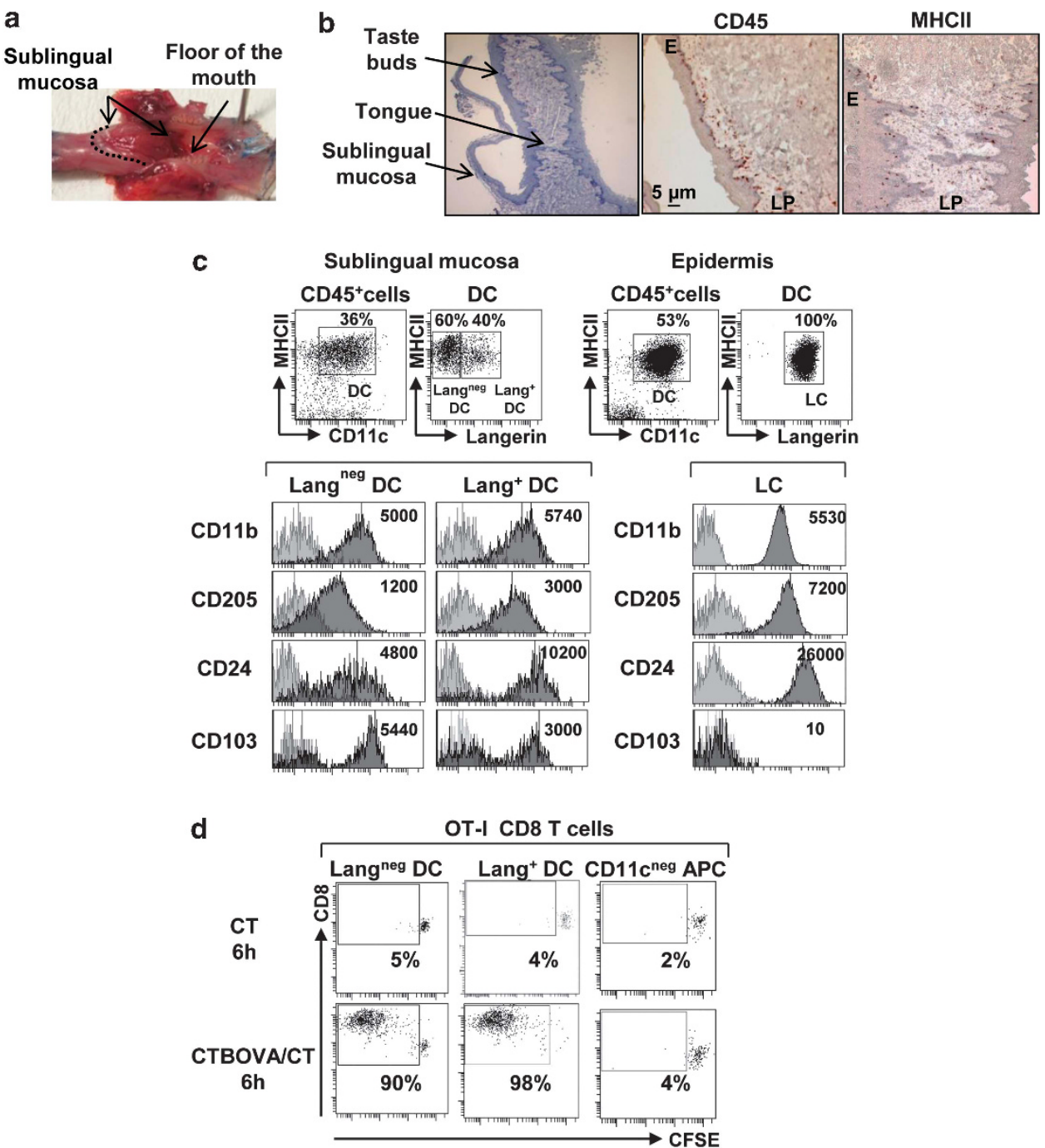

Figure 1 Sublingual dendritic cells (DCs) present a vectorised ovalbumin applied on the sublingual mucosa to specific T cells. (a) Macroscopic view of the lower jaw showing the sublingual mucosa beneath the tongue. (b) Hematoxylin staining of longitudinal sections of the tongue and the sublingual mucosa (left panel). Sublingual distribution of hematopoetic cells (CD45 ${ }^{+}$, middle panel) and $\mathrm{MHCII}^{+}$cells (right panel) after immunohistochemical staining. (c) $\mathrm{CD} 11 \mathrm{c}^{+} \mathrm{MHCII}^{+} \mathrm{DCs}$ from the sublingual mucosa and the epidermis of transgenic Lang-EGFP mice were analyzed by flow cytometry after surface stainings with monoclonal antibodies against CD45, CD11c, MHCII, CD11b, CD205, CD24, and CD103. The expression levels of different markers by gated sublingual DCs (left panel) and Langerhans cells (LC) (right panel) are shown in dark grey histograms. Light grey histograms represent isotype controls. Numbers in the histogram plots indicate the mean fluorescence intensity for each marker. (d) Sublingual DCs and $\mathrm{MHCll}{ }^{+} \mathrm{CD} 11 \mathrm{c}^{\text {neg }}$ antigen-presenting cells $\left(\mathrm{CD} 11 \mathrm{c}^{\text {neg }} \mathrm{APC}\right)$ were isolated from the sublingual mucosa $6 \mathrm{~h}$ after sublingual immunization with CTBOVA (ovalbumin antigen conjugated to the Cholera toxin B subunit) and Cholera toxin (CT; CTBOVA/CT 6h) or with CT only (CT 6h). Sorted populations were co-cultured with naive CFSE (carboxyfluorescein diacetate succinimidyl ester)-labeled OVA-specific CD8 T cells (OT-I CD8 T cells) at a T/DC ratio $=10 / 1$ during 5 days without any addition of exogenous antigenic peptide. Dot plots represent the CFSE dilution of OT-I CD8 T cells accounting for their specific proliferation. Data are representative of three independent experiments. E, epithelium; LP, lamina propria; MHC, major histocompatibility complex. 
expressed the langerin marker typically expressed by epidermal Langerhans cells (LC) and by a subset of dermal DCs (Figure 1c and data not shown). Forty percent of sublingual Lang ${ }^{+}$DCs expressed CD103 and could represent the equivalent of dermal Lang $^{+}$DCs, whereas the sublingual $\mathrm{CD} 103^{\text {neg }}$ Lang $^{+}$DCs could correspond to LC. Sublingual Langerin ${ }^{\text {neg }}$ DCs (Lang ${ }^{\text {neg }}$ DCs) expressed CD11b, CD205, and CD24 markers but at lower levels than sublingual Lang ${ }^{+}$DCs and LC (Figure 1c). Interestingly, sublingual Lang ${ }^{\text {neg }}$ DCs were positive for CD103 expressed by mucosal DCs living in the gut but not described in the skin (Figure 1c and Merad et al. ${ }^{15}$ ).

We then asked whether sublingual DCs were able to present an antigen administered by sublingual route. We used CTBOVA as antigen. CT was used as mucosal adjuvant. The kinetics of ex vivo presentation of the CD8 OVA epitope by sublingual DCs and $\mathrm{MHCII}^{+} \mathrm{CD} 11 \mathrm{c}^{\text {neg }} \mathrm{APC}\left(\mathrm{CD} 11 \mathrm{c}^{\text {neg }} \mathrm{APC}\right)$ was analyzed between 6 and $24 \mathrm{~h}$ after sublingual immunization. Sublingual Lang ${ }^{\text {neg }}$ DCs and Lang ${ }^{+}$DCs were then sorted out and cultured in vitro with naive carboxyfluorescein diacetate succinimidyl ester (CFSE)-labeled OT-I CD8 T cells during 5 days without any addition of antigenic peptides. Sublingual DC subsets isolated $6 \mathrm{~h}$ after immunization induced the proliferation of OT-I CD8 T cells with similar efficiency (90\% and 98\%) contrary to CD11 ${ }^{\text {neg }}$ APC and DC subsets from the CT control group (Figure 1d). OVA antigen presentation by sublingual DCs peaked between 6 and $12 \mathrm{~h}$ and then decreased at $24 \mathrm{~h}$ and was restricted to sublingual DCs (data not shown).

These data show that sublingual DCs have efficiently captured the antigen. Moreover, both sublingual Lang ${ }^{+}$ DCs and Lang ${ }^{\text {neg }}$ DCs are equipped to cross-prime CD8 T-cell epitopes.

\section{Muc-derived DCs from submandibular and cervical lymph nodes (CLN) cross-prime CD8 T cells in a time-dependent manner}

Sublingual DCs were able to present the antigen administered by sublingual route, as antigen-bearing DCs are transiently detected in the mucosa after local immunization (Figure 1d) and then in the SMLN. ${ }^{12}$ We then wondered whether the priming of CD8 $\mathrm{T}$ cells exclusively occurred in SMLN or whether CD8 $\mathrm{T}$ cells could also be primed in other lymphoid organs after sublingual immunization.

To avoid any confusion regarding the name of the lymph nodes of the buccal area, we used the nomenclature proposed by Van Den broeck et al. ${ }^{16}$ and Harrel et al. ${ }^{17}$ The SMLN are localized above the salivary glands and the CLN appear along the jugular vein (Figure 2a). To identify the lymph nodes draining the sublingual mucosa, Evans blue dye was injected in the sublingual mucosa and the lymph nodes analyzed. The SMLN were stained as early as $30 \mathrm{~min}$ after dye injection, whereas the CLN were not, showing that the SMLN represented the lymph nodes draining the sublingual mucosa (Figure 2b). We were not able to visualize lymphatics between SMLN and CLN, nor the staining of the CLN at this early time point, suggesting that CLN were not downstream from SMLN efferent lymph. Other lymph nodes and skin were stained between 2 and $6 \mathrm{~h}$ after treatment, suggesting that the dye rapidly diffused through vessels (data not shown).

We then evaluated the antigen presentation by distinct DC subsets from the SMLN and the CLN. DC subsets were purified from the lymph nodes on the basis of the co-expression of the integrin $\mathrm{CD} 11 \mathrm{c}$, and the MHCII molecule and their ability to induce the proliferation OT-I CD8 T cells was measured at different time points. SMLN DCs efficiently induced the proliferation of OT-I CD8 T cells 12 and $24 \mathrm{~h}$ after sublingual immunization with CTBOVA/CT contrary to SMLN CD $11 c^{\text {neg }}$ APC and CT-treated control (Figure 2c, upper panel). Interestingly, CLN DCs induced a notable proliferation of OT-I CD8 T cells $24 \mathrm{~h}$ after immunization, suggesting that sublingual DCs have emigrated in CLN or that the sublingual antigen has diffused by itself through blood circulation (Figure 2c, lower panel). We then examined the nature of the LN DC subsets able to prime the OT-I CD8 T cells in the SMLN and in the CLN. We identified three major DC subsets: CD11 $c^{\text {int }} \mathrm{MHCII}^{\text {high }}$ DCs corresponding to mucosa-derived DCs (Muc-DCs), CD11 $\mathrm{c}^{\text {high }} \mathrm{MHCII}^{\text {int }}$ corresponding to conventional blood-derived DCs (cDCs) and blood-derived $\mathrm{CD} 11 \mathrm{c}^{\mathrm{int}} \mathrm{MHCII}{ }^{\mathrm{int}}$ plasmacytoid DCs (pDCs) expressing the B220 marker (Figure 2d). We sorted out these DC subsets from the SMLN and the CLN 24 and $48 \mathrm{~h}$ following sublingual immunization with CTBOVA/CT or with CT. Their ability to induce the proliferation of OT-I CD8 $\mathrm{T}$ cells at different T/DC ratio was measured. Muc-DCs from the SMLN represented the major DC subset inducing CD8 T-cell proliferation 24 and $48 \mathrm{~h}$ after immunization contrary to $\mathrm{cDCs}$ and $\mathrm{pDCs}$ (Figure 2e,f, upper panels). We also sorted out $\mathrm{CD} 8^{+} \mathrm{CD} 11 b^{\text {neg }}$ blood-DCs, including $67 \%$ of activated MHCII ${ }^{\text {hi }}$ blood-DCs (Supplementary Figure S1a online). $\mathrm{CD}^{+}$blood-DCs did not induce any proliferation excluding the hypothesis that CT-activated blood-DCs could have captured the antigen (Supplementary Figure S1b online). Muc-DCs from the CLN also induced a notable proliferation of OT-I CD8 T cells at a higher T/DC ratio (T/DC ratio: 2.5/1), indicating that antigenbearing DCs have migrated to CLN from the sublingual mucosa. This proliferation was higher at $48 \mathrm{~h}(94 \%)$ than at $24 \mathrm{~h}$ (24\%) (Figure 2e, lower panel). In contrast, Muc-DCs from CT-treated mice did not induce any proliferation of OT-I CD8 T cells (Figure 2e, right panel). Blood-DCs from the SMLN and the CLN were also unable to induce the proliferation of OT-I T cells (Figure 2e and data not shown), demonstrating that the CTBOVA antigen has been mainly captured by sublingual DCs and consequently did not diffuse by itself through the lymph or the blood circulation.

These data demonstrate that the SMLN constitute the primary site of antigen presentation by Muc-DCs after sublingual immunization. Our data also indicate that antigen-bearing DCs are able to migrate in the CLN.

SMLN are not mandatory to generate CD8 T-cell responses We showed that Muc-DCs from the SMLN and the CLN were able to present the sublingual antigen to OT-I CD8 T cells in a 

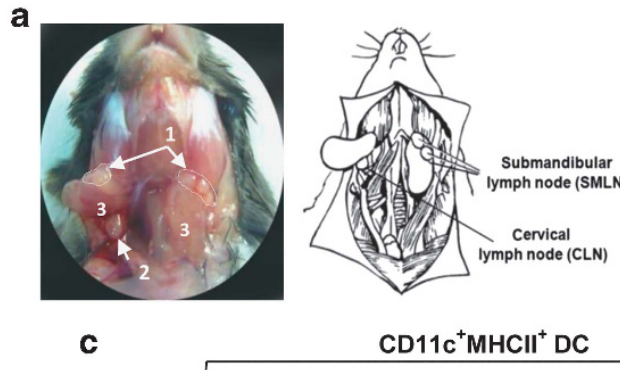

c

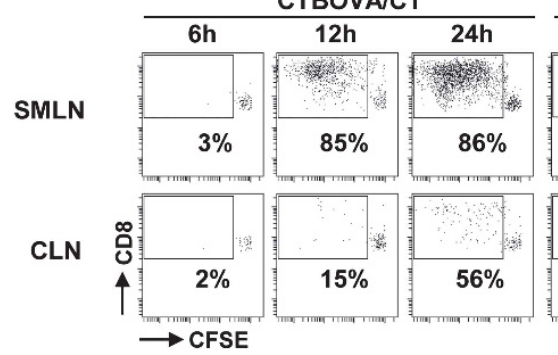

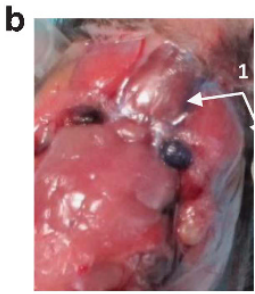

$\mathrm{CD}_{11 c^{\text {neg }}}$ APC CTBOVAVT

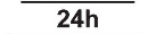

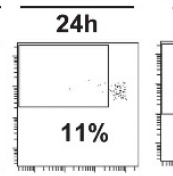
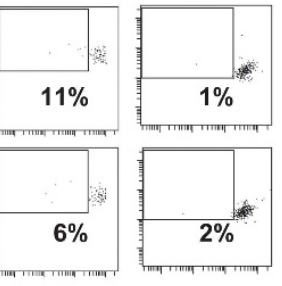

d

e

Muc-DC
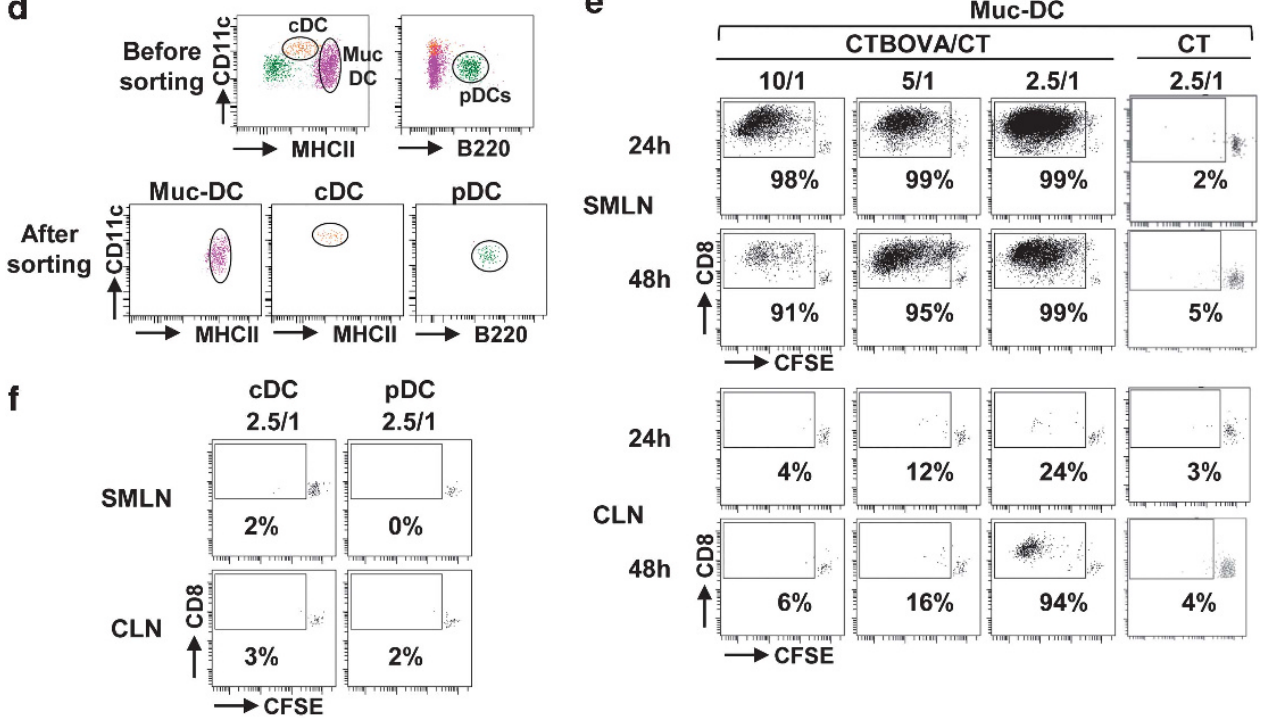

Figure 2 Mucosa-derived dendritic cells (Muc-DCs) from the submandibular lymph nodes (SMLN) and the cervical lymph nodes (CLN) cross-prime CD8 T cells in a time-dependent manner. (a) Macroscopic view of the throat showing the SMLN (1), the CLN (2), and the salivary glands (3) (left panel) according to the schematic drawing of the SMLN and the CLN adapted from Wolvers et al. ${ }^{23}$ (right panel). (b) Macroscopic view of the SMLN (1) and the CLN (2) from a C57BL/6 mouse injected with Evans blue dye, showing the blue staining of the SMLN 30 min after injection (1). (c-f) C57BL/6 mice were immunized with CTBOVA (ovalbumin antigen conjugated to the Cholera toxin B subunit) and Cholera toxin (CT) or with CT. DC subsets and $\mathrm{MHClI}^{+} \mathrm{CD} 11 \mathrm{c}^{\text {neg }}$ antigen-presenting cells (CD11 $\left.{ }^{\text {neg }} \mathrm{APC}\right)$ from the SMLN and the CLN were sorted out at different time points after immunization $(6,12,24$, and $48 \mathrm{~h}$ ). Their ability to prime naive CFSE (carboxyfluorescein diacetate succinimidyl ester)-labeled OVA-specific CD8 T cells (OT-I CD8 T cells; 100,000 cells) at different T/DC ratio was analyzed by measuring CFSE dilution by flow cytometry after 5 days of culture. (c) Sorted CD11c ${ }^{+} \mathrm{MHCII}^{+}$DCs and CD11 $\mathrm{c}^{\text {neg }}$ APC from the SMLN (upper panel) and from the CLN (lower panel) were cultured with CSFE-labeled OT-I CD8 T cells at a T/DC ratio of 10/1 for DCs and 1/1 for APC. Bold numbers in dot plots indicate the percentage of dividing OT-I CD8 T cells. (d) SMLN and CLN DC subsets were sorted out in MHCII ${ }^{\text {high }}$ DCs (Muc-DCs), blood-derived DCs (conventional and plasmacytoid DCs (cDCs and pDCs, respectively)) based on CD11c, MHClI, and B220 expression. (e, f) SMLN and CLN Muc-DCs (e) and Blood-DCs (including cDCs and pDCs) (f) were then cultured with CFSE-labeled OT-I CD8 ${ }^{+}$T cells at different T/DC ratios (10/1,5/1, and 2.5/1) during 5 days. Bidimensional dot plots show the

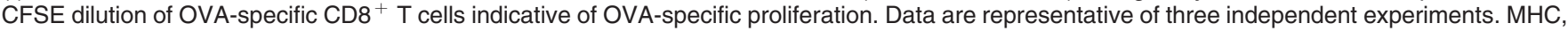
major histocompatibility complex.

time-dependent manner. Our previous work demonstrated that sublingual prime-boost immunization with CTB-based vaccines induced the differentiation of cytotoxic CD8 T lymphocytes disseminating to the female genital mucosa. ${ }^{8,9}$ The next question was whether the antigen presentation observed in CLN was sufficient to generate genital cytotoxic CD8 T cells. Wild-type mice and SMLN-removed mice were immunized with CTBOVA and CT. Seven days after the third immunization, the OVA-specific cytolysis was measured using an in vivo cytolysis assay. We observed an in vivo comparable cytolysis in the spleen $(36 \% \pm 5 \mathrm{vs} .33 \% \pm 5), \operatorname{CLN}(36 \% \pm 5 \mathrm{vs}$. $44 \% \pm 5)$, ileo-sacral lymph nodes ( $35 \% \pm 4$ vs. $34 \% \pm 4$ ), and genital mucosa (18\% \pm 4 vs. $15 \% \pm 4)$ of wild-type mice and SMLN-removed mice (Figure 3a, black and grey bars, 


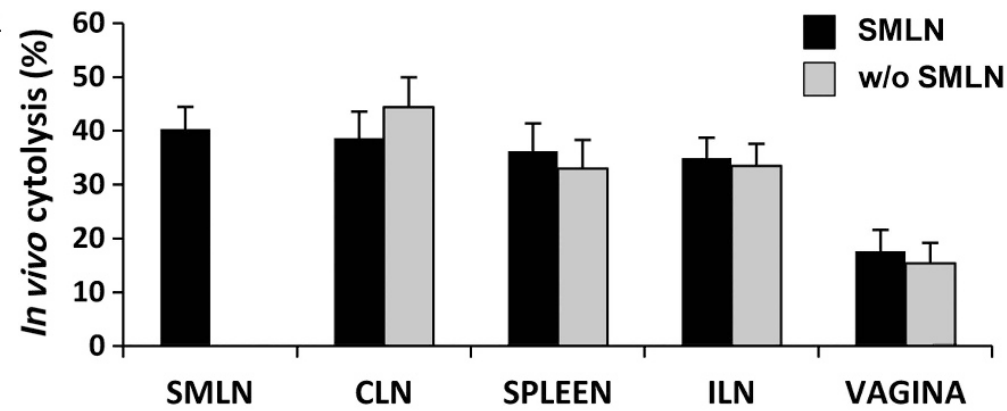

b CT CTBOVA+CT
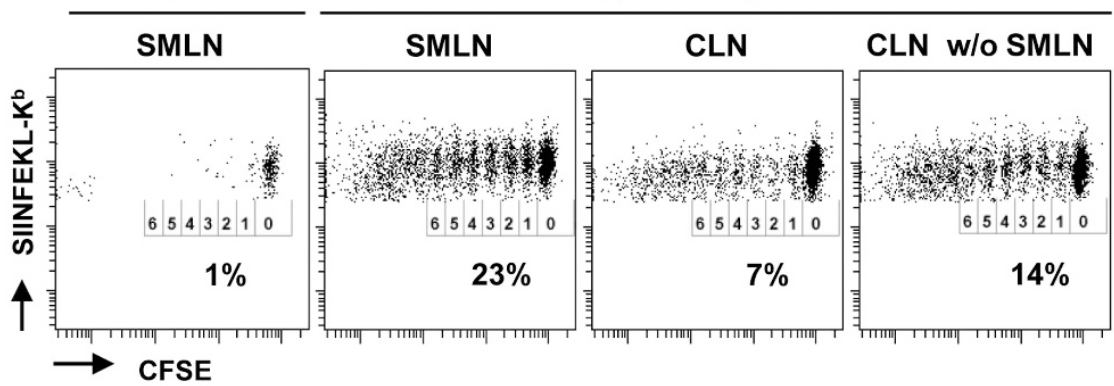

C

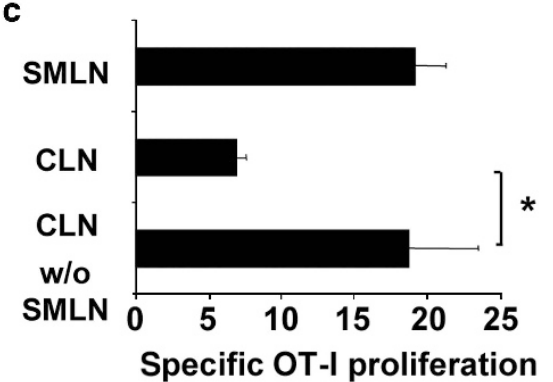

(\%)

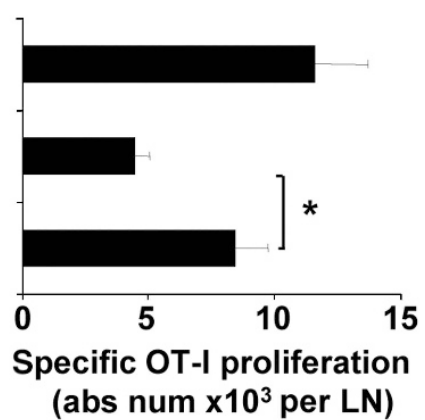

(abs num $\times 10^{3}$ per LN)

d

Muc-DC

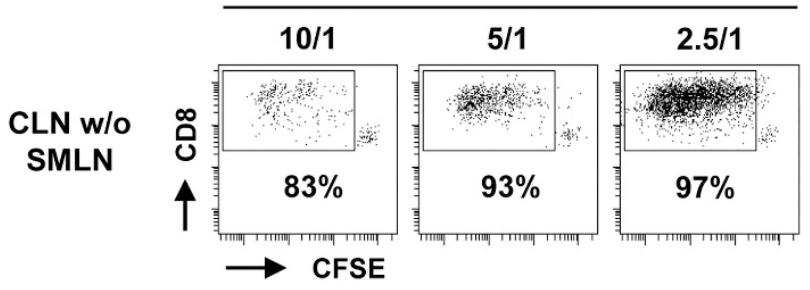

Figure 3 Submandibular lymph nodes (SMLN) are not mandatory to generate systemic and vaginal CD8 ${ }^{+}$cytotoxic T cells after sublingual immunization. (a) Groups of wild-type mice ( $n=22$; black bars) or C57BL/6 mice in which SMLN were surgically removed ( $n=12$; gray bars) received three consecutive sublingual immunizations with CTBOVA (ovalbumin antigen conjugated to the Cholera toxin $B$ subunit) in presence of Cholera toxin (CT) at days 1, 14, and 21. The ovalbumin (OVA)-specific cytolysis was measured after intravenous and intravaginal injections of SIINFEKL-pulsed CFSE $^{\text {high }}$ and unpulsed CFSE ${ }^{\text {low }}$ target cells. Specific cytolysis was assessed in SMLN, cervical lymph nodes (CLN), spleen, ileo-sacral lymph nodes (ILN), and vagina by flow cytometry. Histograms correspond to means (+ s.e.m.) of percentages of specific cytolysis calculated as indicated in Methods. Data are from five independent experiments. (b, c) Non-operated mice and mice without SMLN were adoptively transferred with naive CFSE (carboxyfluorescein diacetate succinimidyl ester)-labeled OVA-specific CD8 T cells (OT-I CD8 T cells) and immunized 1 day later with CTBOVA and CT or CT alone. The in vivo proliferation of OT-I CD8 T cells was evaluated 5 days later by measuring CFSE dilution in the SMLN and the CLN following specific staining with CD8 $\alpha$ and major histocompatibility complex (MHC) class I H-2Kb/SIINFEKL pentamer. (b) Bidimensional diagrams represent the specific proliferation of gated SIINFEKL ${ }^{+} \mathrm{CD} 8^{+} \mathrm{T}$ cells for a representative experiment. Percentages in dot plots correspond to the percentage of dividing cells. (c) Histograms represent the mean value (+s.e.m.) of the percentage of specific OT-I proliferating cells (left panel) and the mean value (+s.e.m.) of OT-I T-cell numbers per lymph node. Data are from five independent experiments $\left(n=15\right.$ per group). ${ }^{*}$ Denotes statistical significance. (d) CLN MHCII ${ }^{\text {high }}$ DCs (mucosa-derived dendritic cells (Muc-DCs)) from mice without SMLN were sorted out $48 \mathrm{~h}$ after sublingual immunization with CTBOVA and CT and cultured with CFSE-labeled OT-I CD8 T cells at different T/DC ratios (10/1, 5/1, and 2.5/1) during 5 days. Bidimensional dot plots show the CFSE dilution of OT-I CD8 T cells indicative of OVA-specific proliferation. Data are representative of three independent experiments. 
respectively). We carefully checked that the SMLN were absent at the time of the analysis. Thus, the SMLN were dispensable for the generation of cytotoxic OVA-specific CD8 T lymphocytes in the proximal and distant lymphoid organs and in the female genital mucosa (Figure 3a) which could be explained by the observation that Muc-DCs from CLN were also able to present the antigen administered by sublingual route (Figure $2 \mathbf{c}, \mathbf{e}$ ). We then evaluated whether OT-I CD8 T cells were primed in CLN using SMLN-removed mice. CFSE-labeled OT-I CD8 $\mathrm{T}$ cells were transferred either in control recipients or in SMLN-removed mice. Mice were immunized with CTBOVA and CT, and OVA-specific CD8 T-cell proliferation was analyzed 5 days later in the SMLN and CLN. The sublingual immunization with CTBOVA and CT induced a strong proliferation of OT-I CD8 T cells $(20 \pm 3 \%$ proliferating cells), whereas no proliferation was observed in mice which received only CT ( $1 \%$ proliferating cells; Figure $3 \mathbf{b}, \mathbf{c}$ ). A low but significant proliferation of OT-I CD8 T cells $(7 \pm 1 \%$ proliferating cells) was observed in the CLN of mice immunized with CTBOVA and CT. Furthermore, we observed a significant increase in the frequency and numbers of OT-I CD8 T cells per LN after immunization in SMLN-removed mice compared with non-operated mice (18 $\pm 5 \%$ vs. $7 \pm 1 \%$ proliferating cells and $8,425 \pm 1,300$ vs. $4,500 \pm 570$ ) (Figure 3b,c), confirming that the SMLN represent the primary site of priming after sublingual immunization and that priming can occur in CLN too. Accordingly, the presentation of the antigen by the Muc-DCs from the CLN of operated mice was increased compared with non-operated mice (Figures $\mathbf{3 d}$ and $\mathbf{2 e}$ ). This suggests that antigen-bearing DCs can migrate to the CLN from the sublingual mucosa and can contribute to the priming of CD8 T cells.

\section{CD8 T-cell priming also occurs in systemic locations}

We then asked whether such priming occurs in systemic locations. We analyzed the priming of OT-I CD8 T cells in the ileo-sacral lymph nodes (genital nodes) draining the genital mucosa, brachial lymph nodes (cutaneous nodes) draining the skin, and spleen after sublingual immunization from nonoperated mice and from mice in which SMLN and CLN were removed. A weak but reproducible proliferation of OT-I CD8 T cells was observed in the genital and cutaneous lymph nodes and in the spleen of non-operated mice (Figure 4a, upper panel and Figure 4b). We observed a slight decrease of the frequency OT-I CD8 T cells but no modulation of OT-I CD8 T-cell numbers in distant lymph nodes and in spleen after ablation of SMLN and CLN compared with control non-operated mice (Figure 4a lower panel and Figure 4b). Furthermore, the first rounds of CD8 T-cell divisions were observable in the distant lymph nodes and spleen in non-operated mice 3 and 5 days post immunization (Supplementary Figure S2 online and Figure 4, respectively), suggesting that antigen-specific proliferation also occurs in distant lymphoid organs after sublingual immunization. We then wondered whether distant lymphoid organs were mandatory to generate OT-I CD8 T cells
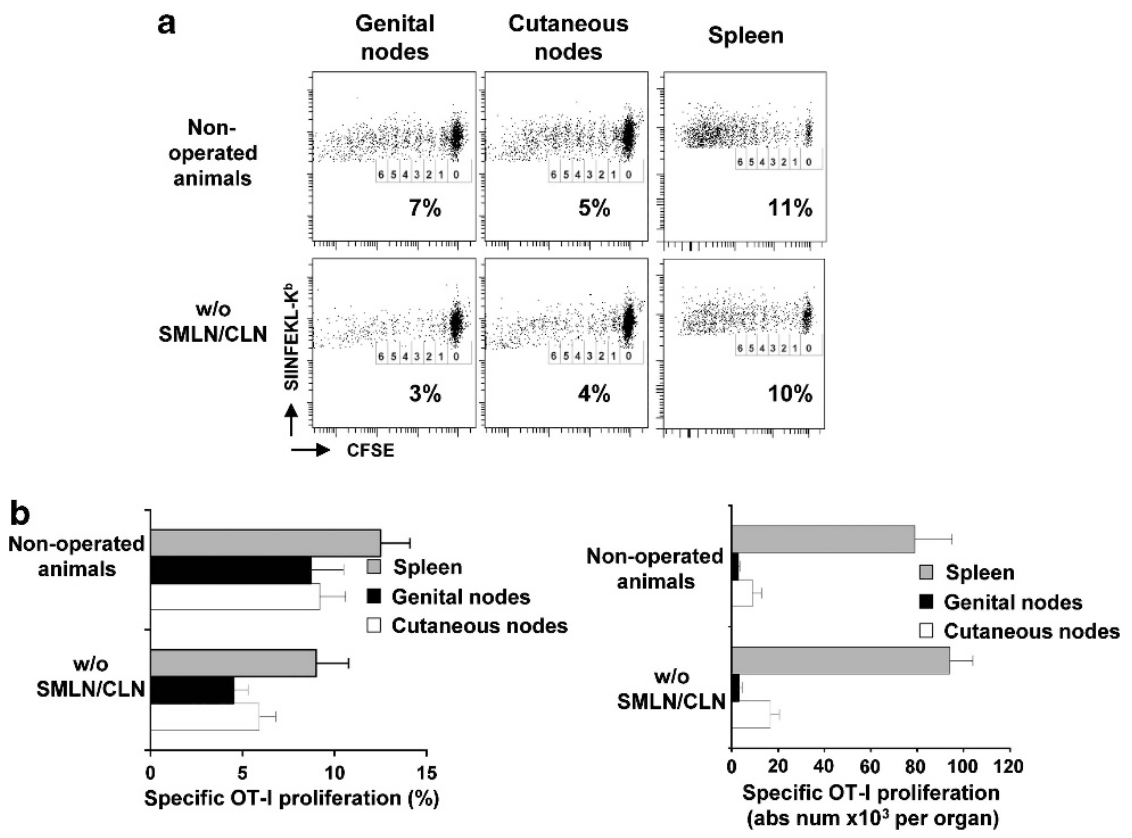

Figure 4 The priming of OVA-specific CD8 T cells (OT-I CD8 T cells) after sublingual immunization also occurs in distant lymphoid organs. C57BL/6 wild-type mice (non-operated) and mice without submandibular lymph nodes (SMLN) and cervical lymph nodes (CLN) (w/o SMLN/CLN) received naive CFSE (carboxyfluorescein diacetate succinimidyl ester)-labeled OT-I T cells by intravenous injection. One day later, mice were immunized sublingually with CTBOVA (ovalbumin antigen conjugated to the Cholera toxin (CT) B subunit) and CT. The in vivo proliferation of OT-I CD8 T cells was evaluated 5 days later by measuring the CFSE dilution in genital nodes, cutaneous nodes, and spleen. (a) Bidimensional diagrams represent the proliferation of OT-I CD8 T cells in the genital nodes, cutaneous nodes, and spleen. The percentages correspond to the dividing OT-I CD8 ${ }^{+}$ T cells for a representative experiment. (b) Histograms represent the mean value (+ s.e.m.) of the percentage of dividing OT-I CD8 T cells and the mean value $(+$ s.e.m.) of the numbers of OT-I CD8 T cells per organ. Data are from five independent experiments. 
migrating to the genital mucosa. We analyzed OT-I CD8 T cells in the genital mucosa after a prime/boost sublingual immunization with CTBOVA and CT in mice without genital nodes (w/o genital nodes) or without SMLN and CLN (w/o SMLN/CLN) compared with non-operated mice. The ablation of either distant lymph nodes (genital nodes) or local lymph nodes (SMLN and CLN) did not affect the percentages of OT-I CD8 T cells generated by sublingual immunization compared with non-operated control (non-operated mice, $n=6: 19 \pm 4 \%$ OT-I CD8 T cells vs. mice w/o SMLN/CLN, $n=6: 17 \pm 4 \%$ vs. mice w/o genital nodes, $n=11: 18 \pm 3 \%$ ) (Supplementary Figure S3 online). The ratio of OT-I CD8 T cells compared with total CD8 T cells is the same in all the groups analyzed (non-operated mice, $n=6$, mean OVA CD8 T cells/CD8 T cells ratio:0.2 vs. mice w/o SMLN/CLN, $n=6$, mean OVA CD8 T cells/CD8 T cells ratio:0.18 vs. mice w/o genital nodes, $n=11$ : 0.19 ) even if the ablation of the genital nodes induced a twofold increase of the cellularity in the genital mucosa compared with the other groups (data not shown), which is also observable in the pool of OT-I CD8 T cells and total CD8 T cells.

Altogether, these data demonstrate that the priming of OT-I $\mathrm{CD} 8 \mathrm{~T}$ cells can occur in local lymph nodes and distant lymphoid organs and that the ablation of local or distant lymph nodes did not affect the generation of genital effector CD8 T cells.

\section{Muc-DCs migrate in distant lymphoid organs}

If priming can occur in distant lymphoid organs after sublingual immunization, antigen-bearing DCs from the sublingual mucosa should be able to migrate to distant lymphoid organs to contribute to the generation of effector CD8 $\mathrm{T}$ cells. To reinforce this hypothesis, we then asked whether DC subsets from the genital nodes, cutaneous lymph nodes and spleen were capable to present the OVA epitope to OT-I CD8 $\mathrm{T}$ cells after sublingual immunization with CTBOVA and CT. Muc-DCs and blood-DCs (cDCs and pDCs) from the genital and cutaneous nodes were sorted out $48 \mathrm{~h}$ after sublingual immunization from without SMLN and CLN. Genital and cutaneous Muc-DCs were able to induce the proliferation of OT-I CD8 T cells as measured by CFSE dilution in a dose-dependent manner and by the presence of OT-I CD8 T blast cells (Figure 5a) contrary to DCs from CT-immunized mice (Figure 5b). Furthermore, blood-DCs were inefficient to prime OT-I CD8 T cells at different T/DC ratio $48 \mathrm{~h}$ after immunization (Figure 5c and data not shown). Splenic DCs were sorted out in $\mathrm{MHCII}{ }^{\text {hi }} \mathrm{DCs}, \mathrm{MHCII}{ }^{\text {int }} \mathrm{CD} 8^{+} \mathrm{DCs}$, and $\mathrm{MHCII}^{\text {int }} \mathrm{CD} 1 \mathrm{~b}^{+}$DCs $48 \mathrm{~h}$ after sublingual immunization with CTBOVA and CT (Figure 6a), and their ability to present the OVA epitope to OT-I CD8 T cells was analyzed. Proliferation induced by SMLN Muc-DCs obtained in the

$\mathbf{a}$ CTBOVA/CT Muc-DC

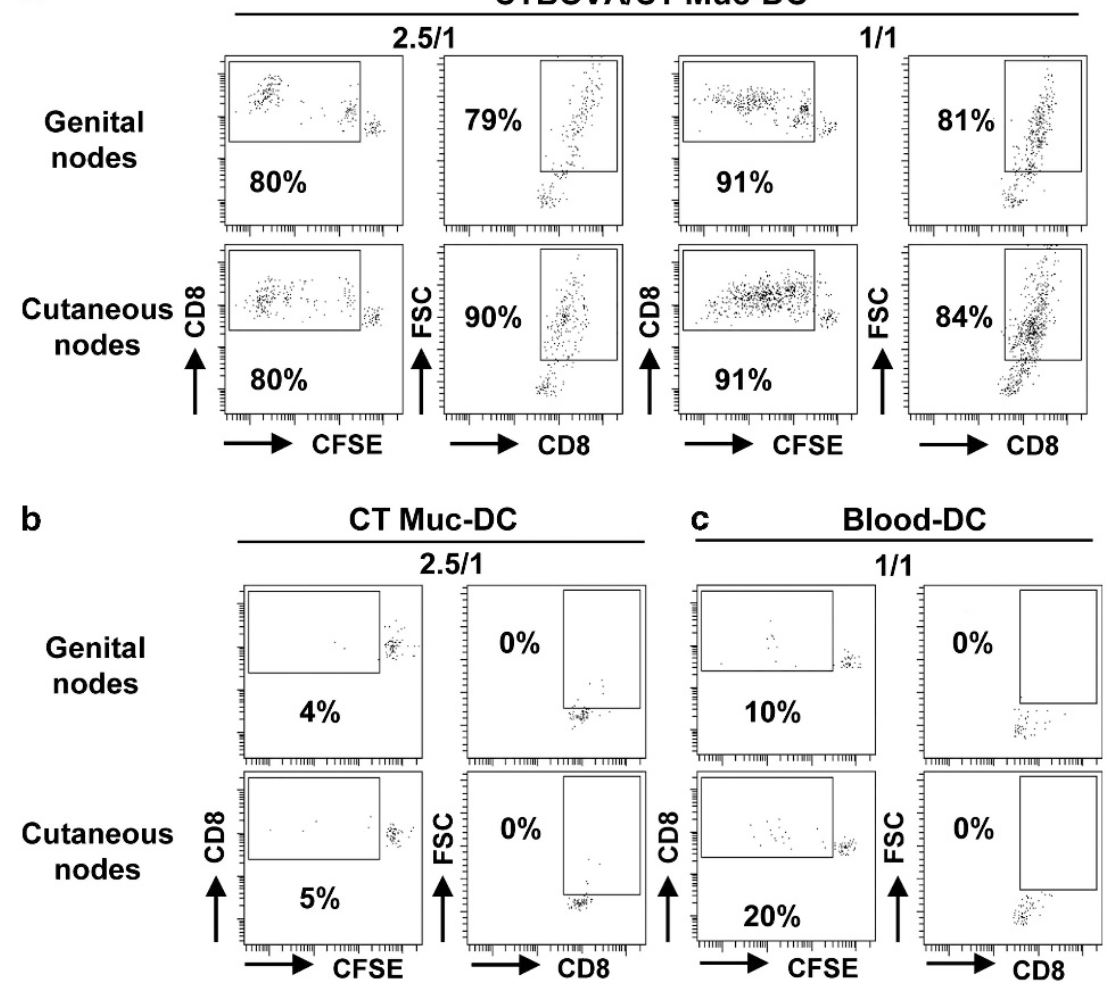

Figure 5 Dendritic cells (DCs) from distant lymph nodes cross-prime OVA-specific $\mathrm{CD}^{+}{ }^{+} \mathrm{T}$ cells after sublingual immunization. The submandibular lymph nodes and cervical lymph nodes were removed from C57BL/6 mice. Cells from genital and cutaneous lymph nodes were prepared $48 \mathrm{~h}$ after sublingual immunization with CTBOVA (ovalbumin antigen conjugated to the Cholera toxin B subunit) and Cholera toxin (CT) or CT. DC subsets were sorted out in (a, b) mucosa-derived dendritic cells (Muc-DCs) or (c) blood-DCs and were cocultured with CFSE (carboxyfluorescein diacetate succinimidyl ester)-labeled OVA-specific CD8 T cells (OT-I CD8 T cells) at two T/DC ratio (2.5/1 and 1/1) during 5 days. Specific proliferation was measured by CFSE dilution of gated OT-I CD8 T cells by flow cytometry. Bidimensional diagrams show the expression of CD8 vs. CFSE dilution and FSC (forward side scatter) vs. CD8 parameters. Percentages in dot plots represent the frequency of dividing CFSE-labeled OT-I CD8 T cells and the frequency of blastic CD8 ${ }^{+} \mathrm{T}$ cells. Results are representative of three independent experiments. 
a

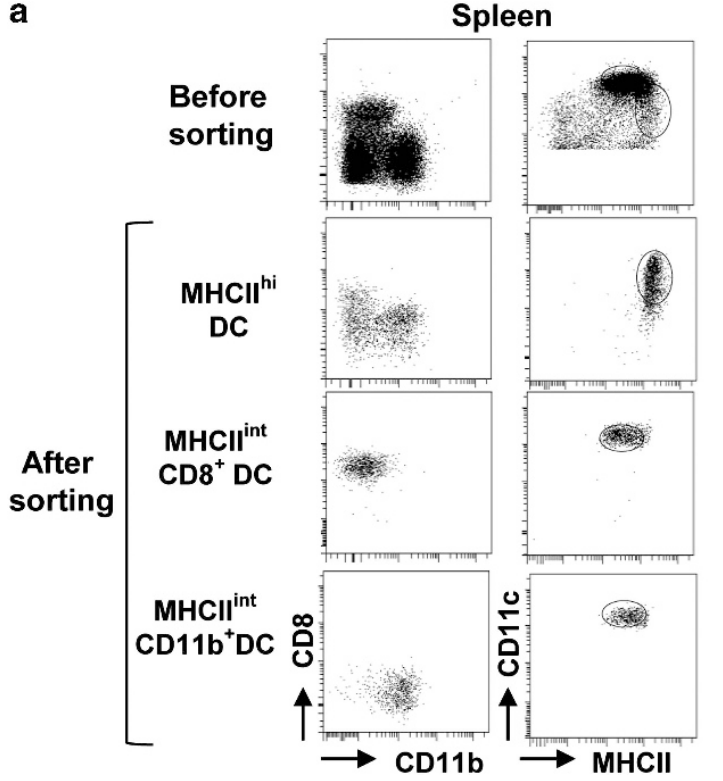

b OT-I proliferation

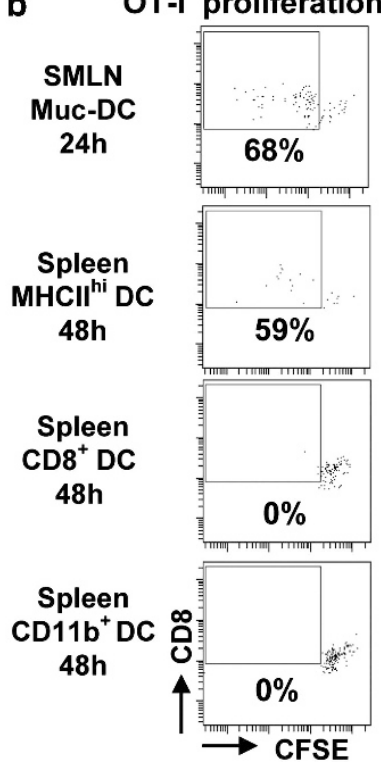

Figure 6 Splenic $\mathrm{MHCII}^{\text {hi }}$ dendritic cells (DCs) cross-prime OVA-specific CD8 ${ }^{+}$T cells (OT-I CD8 T cells) after sublingual immunization. The submandibular lymph nodes (SMLN) and the cervical lymph nodes were removed from C57BL/6 mice. Splenocytes were prepared $48 \mathrm{~h}$ after sublingual immunization with CTBOVA (ovalbumin antigen conjugated to the Cholera toxin B subunit) and Cholera toxin (CT) or CT. (a) DC subsets were sorted out in $\mathrm{MHCII}^{\mathrm{hi}} \mathrm{DC}$ s or $\mathrm{MHCII}^{\text {int }} \mathrm{CD} 8^{+}$and $\mathrm{MHCII}^{\text {int }} \mathrm{CD} 11 \mathrm{~b}^{+}$DC subsets. (b) Sorted DC subsets were cocultured with CFSE (carboxyfluorescein diacetate succinimidyl ester)-labeled naive OT-I CD8 T cells at a 1/1 T/DC ratio during 5 days. In the same experiment, SMLN Muc-DCs isolated $24 \mathrm{~h}$ after immunization were cocultured with CFSE-labeled naive OT-I CD8 T cells at a T/DC ratio of 10/1 during 5 days. Specific proliferation was analyzed by measuring the CFSE dilution of gated OT-I CD8 T cells by flow cytometry. Bidimensional diagrams

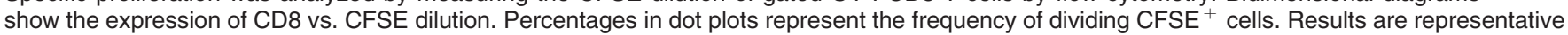
of two independent experiments. MHC, major histocompatibility complex.

same experiment was also included. Splenic MHCII ${ }^{\text {hi }}$ DCs induced the proliferation of OT-I CD8 T cells, whereas splenic $\mathrm{MHCII}^{\text {int }}$ DC subsets $\left(\mathrm{CD}{ }^{+}\right.$and $\left.\mathrm{CD}^{+} 1 \mathrm{~b}^{+}\right)$did not (Figure 6b). This result put together with the observation that activated $\mathrm{MHCII}{ }^{\mathrm{hi}} \mathrm{CD} 8{ }^{+}$DCs from the SMLN were not capable to present the antigen to OT-I CD8 T cells (Supplementary Figure S1 online) suggests that splenic antigen-bearing DCs represent recent emigrants from the sublingual mucosa rather than conventional DCs activated in the spleen after sublingual immunization. In order to exclude that DC migration to distant lymphoid organs is mainly due to the ablation of draining lymph nodes, we asked whether Muc-DCs from the genital nodes and spleen from nonoperated mice were able to cross-prime OVA-specific $\mathrm{CD} 8{ }^{+} \mathrm{T}$ cells. DC subsets from wild-type mice were sorted out $48 \mathrm{~h}$ after sublingual immunization with CTBOVA and CT and co-cultured with OTI CD ${ }^{+}$T cells at a DC/T ratio $=2 / 1$ during 5 days. Muc-DCs from the CLN, genital nodes and spleen were able to induce the proliferation of antigen-specific CD8 T cells even less efficiently than Muc-DCs from draining SMLN (Figure 7). Blood DCs and pDCs from these mice were not able to induce any antigen-specific proliferation (data not shown).

In addition, we analyzed the ability of CD $45.2^{+}$DCs transferred in the sublingual mucosa of $\mathrm{CD} 45.1^{+}$recipients to migrate in the SMLN and spleen after sublingual immunization. We compared the frequency of $\mathrm{CD} 45.2^{+} \mathrm{MHCII}^{+}$ CD11c ${ }^{+}$DCs in the SMLN of CD45.1 recipients that received either Muc-DCs or bone marrow-derived DCs (BM-DCs) $24 \mathrm{~h}$ after sublingual immunization with CT. Both DC subtypes were able to migrate in the SMLN (Figure 8a). Due to the limited numbers of mucosal DCs we could obtain, we then analyzed the frequency of CD45.2 $2^{+}$DCs in the spleen of control and CT-immunized recipients after sublingual injection of BMDCs. We detected CD $45.2^{+}$cells, all being $\mathrm{CD} 11 \mathrm{c}^{+} \mathrm{MHCII}^{+}$ DCs, contrary to control recipient mice (Figure $8 \mathbf{b}$ ). The sublingual immunization with CT increased the migration of CD45.2 ${ }^{+}$DCs from the sublingual mucosa to the spleen compared with non-immunized mice $\left(0.3 \%\right.$ vs. $0.1 \%$ CD $45.2^{+}$ DCs) (Figure 8b). Furthermore, the splenic CD45.2 ${ }^{+}$DCs from mice immunized with CT expressed higher levels of MHCII (MHCII mean fluorescence: 36,000 in CD45.2 ${ }^{+}$DCs from immunized mice vs. 28,000 in $\mathrm{CD} 45.2^{+}$DCs from non-immunized mice).

These data demonstrate that MHCII ${ }^{\text {hi }}$ DCs are capable to migrate from the sublingual mucosa to distant lymphoid organs. Interestingly, distant $\mathrm{MHCII}{ }^{\mathrm{hi}} \mathrm{DCs}$ present the antigen acquired after sublingual immunization. As CTBOVA is muco-adhesive and cannot migrate by itself through blood or lymphatic vessels, these data strongly support that antigenbearing DCs have emigrated from the sublingual mucosa to distant inductive sites.

\section{DISCUSSION}

We have shown that antigen-bearing DCs can migrate to distant lymphoid organs where they prime naive CD8 T cells after sublingual immunization. The migration of DCs 


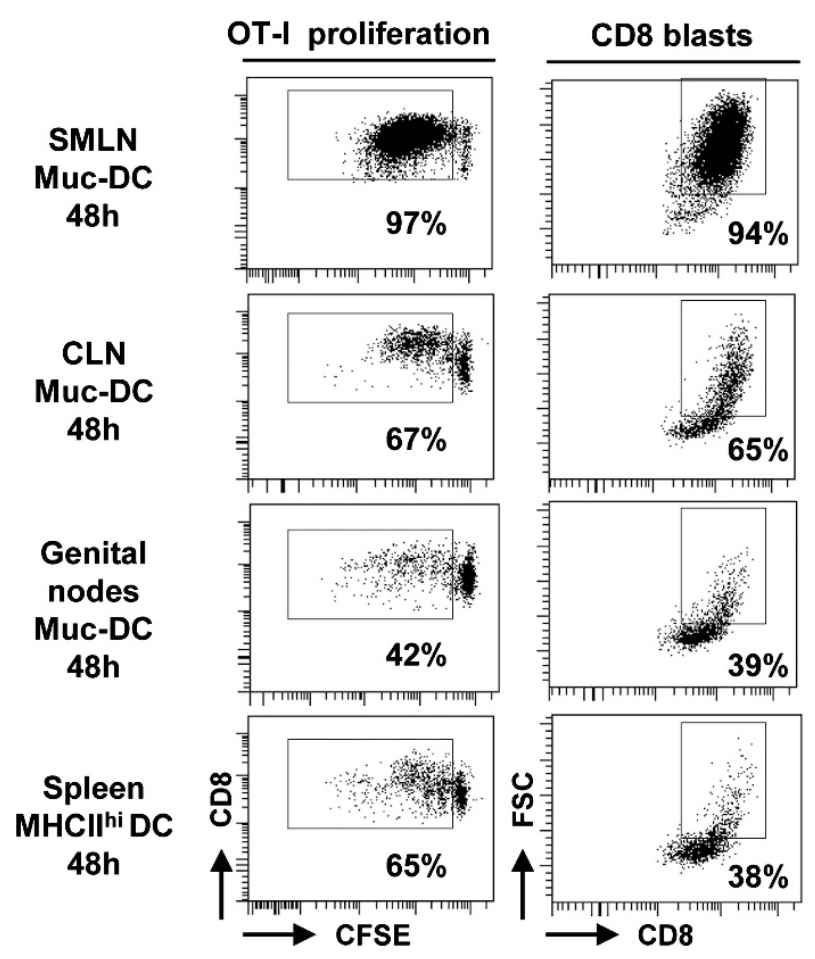

Figure 7 Dendritic cells (DCs) from distant lymph nodes and spleen from non-operated mice cross-prime OVA-specific CD8 ${ }^{+} \mathrm{T}$ cells (OT-I CD8 T cells) after sublingual immunization. Cells from local and distant lymph nodes and spleen were prepared from non-operated mice $48 \mathrm{~h}$ after sublingual immunization with CTBOVA (ovalbumin antigen conjugated to the Cholera toxin (CT) B subunit) and CT. Mucosa-derived dendritic cells (Muc-DCs) were sorted and cocultured with CFSE (carboxyfluorescein diacetate succinimidyl ester)-labeled OT-I CD8 T cells at $\mathrm{T} / \mathrm{DC}$ ratio $=1 / 2$ during 5 days. Specific proliferation was measured by CFSE dilution of gated OT-I CD8 T cells by flow cytometry. Bidimensional diagrams show the expression of CD8 vs. CFSE dilution and FSC (forward side scatter) vs. CD8 parameters. Percentages in dot plots represent the frequency of dividing CFSE-labeled OT-I CD8 T cells and the frequency of blastic CD8 ${ }^{+} \mathrm{T}$ cells. Results are representative of two independent experiments. CLN, cervical lymph nodes; MHC, major histocompatibility complex; SMLN, submandibular lymph nodes.

originating from the sublingual mucosa in distant lymphoid organs represents a previously unappreciated cellular mechanism that can contribute to the generation of effector CD8 T cells in the distant lymphoid organs and genital mucosa.

Our data confirm that the SMLN represent the primary site of T-cell priming by Muc-DCs after sublingual immunization. This observation is complementary to our previous data showing that the sublingual mucosa is a potent immunization site to generate $\mathrm{B}$ - and $\mathrm{T}$-cell responses, which disseminate to the genital mucosa. ${ }^{8,9}$ Plasma cells induced by sublingual immunization were encountered in the genital tract but not in the genital nodes, suggesting that they were mainly primed in the SMLN before recirculating to effector sites. ${ }^{8,18}$ The present study shows that effector CD8 $\mathrm{T}$ cells are encountered in the genital nodes following sublingual immunization. Furthermore, OVA-bearing DCs are also detected in the genital and cutaneous nodes and spleen 2 days after sublingual immunization but not at earlier time points (Figures 2e, 3d, 5-7), which suggests that APC originating from the sublingual mucosa can contribute to the rapid expansion of effector T cells in distant immune sites. Sublingual DCs represent the only APC able to present the sublingual antigen (Figures 1, 2, Supplementary Figure S1 online). This is in accordance with previous report showing that there was no T-cell priming after sublingual immunization in mice depleted in CD11c ${ }^{+}$DCs. ${ }^{19}$

The sublingual mucosa represents an efficient site of administration of medicines ensuring their rapid bio-availability in the blood. We demonstrated that our antigen is presented by the DCs present in SMLN only $24 \mathrm{~h}$ following sublingual immunization (Figure 2), which excludes that the antigen has emigrated by itself through blood and lymphatic vessels. Furthermore, the observation that the sublingual mucosa is an immunocompetent tissue including DC subsets and that sublingual DCs but not other APC were able to present the antigen $6 \mathrm{~h}$ after immunization supports this conclusion (Figure 1). Furthermore, data from Itano et al. ${ }^{20}$ showed that an antigen that migrates by itself from the skin to the draining lymph nodes is encountered at an earlier time point comprised between 4 and $6 \mathrm{~h}$ in the draining lymph node DCs, whereas antigens captured at the immunization site by DCs are detected between 12 and $24 \mathrm{~h}$ after immunization in the lymph nodes. In addition, the CTBOVA antigen used in our study has a high molecular weight and CTB exhibits GM1-binding properties with a high dissociation constant $\left(K^{d}=7.3 \times 10^{-10}\right),{ }^{21}$ properties drastically limiting its free circulation in blood and lymphatic vessels. Furthermore, our previous data demonstrated that adding soluble GM1 with CTBOVA by mucosal route completely abolished the generation of CD8 T cells. ${ }^{10}$

OVA peptides are only presented by tissue-derived DCs expressing high levels of MHCII molecule but not by activated MHCII ${ }^{\mathrm{hi}} \mathrm{CD} 8{ }^{+}$blood-DCs, which strongly supports that our antigen was exclusively taken up in the sublingual mucosa and then carried by migrating antigen-bearing DCs in the draining lymph nodes. This is supported by the observation that sublingually transferred DCs are encountered $24 \mathrm{~h}$ after injection in the SMLN (Figure 8). The same observation was previously reported after vaginal immunization with the same antigen ${ }^{10,12}$ or with a viral antigen. ${ }^{11,22}$ Furthermore, Muc-DCs from the CLN present the antigen after sublingual immunization and their antigen-presenting abilities are increased after surgical removal of draining SMLN. We can hypothetize that the SMLN filter or attract most antigenbearing DCs following sublingual immunization and that their ablation increases the migration of sublingual DCs in local CLN and distant lymphoid organs. Our data contrast with data showing that the SMLN were mandatory to induce immune tolerance following intranasal immunization. ${ }^{23}$ Nevertheless, we can explain these differences by the fact that our immunization conditions are immunostimulatory (due to the presence of a mucosal adjuvant), whereas Wolvers et al. ${ }^{23}$ immunized their mice with a protein in the absence of adjuvant. Moreover, following mucosal or cutaneous immunizations in the presence of a strong adjuvant, we and others have 
a

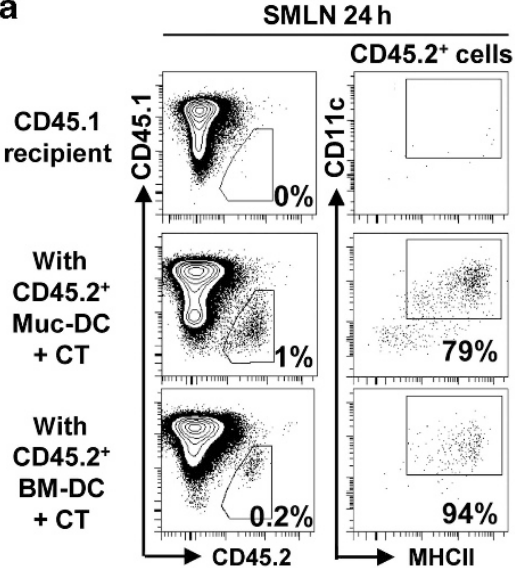

b

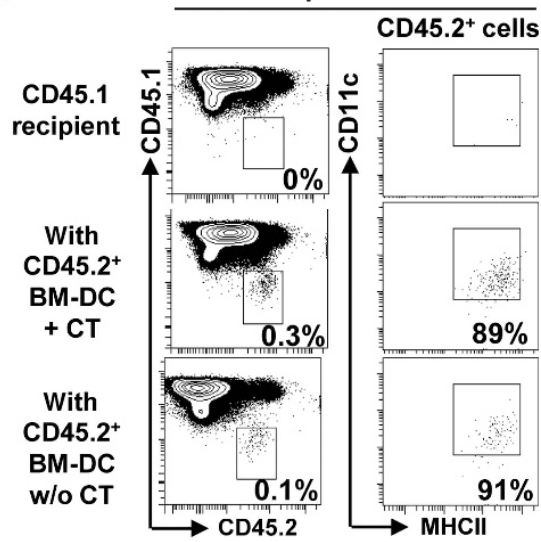

Figure 8 Dendritic cells (DCs) originating from the site of immunization emigrate to the lymph nodes and to the spleen. Mucosal DCs (Muc-DCs) and bone marrow-derived DCs (BM-DCs) were prepared from CD45.2 ${ }^{+}$congenic mice and injected in the sublingual mucosa of CD45.1 ${ }^{+}$ recipients. (a) An enriched fraction of CD45.2 ${ }^{+}$Muc-DCs $\left(4 \times 10^{6} \mathrm{DCs}\right)$ or purified BM-DCs $\left(4 \times 10^{6} \mathrm{DCs}\right)$ were resuspended in $10 \mu \mathrm{l}$ of saline and were injected in the sublingual mucosa of $\mathrm{CD} 45.1^{+}$recipient mice. Mice were immediately immunized with Cholera toxin (CT; $\left.2 \mu \mathrm{g}\right)$ as before, and the frequency of $\mathrm{CD} 45.2^{+} \mathrm{MHCII}^{+} \mathrm{CD} 11 \mathrm{c}^{+} \mathrm{DCs}$ in the submandibular lymph nodes (SMLN) was analyzed by flow cytometry $24 \mathrm{~h}$ after sublingual immunization. (b) CD45.1 $1^{+}$recipient mice in which the SMLN and the cervical lymph nodes were surgically removed, injected with purified BM-DCs $\left(4 \times 10^{6} \mathrm{DCs}\right)$ and immunized or not with CT. The frequency of CD45.2 ${ }^{+} \mathrm{MHClI}^{+} \mathrm{CD} 11 \mathrm{c}^{+} \mathrm{DCs}$ in the spleen was analyzed by flow cytometry $48 \mathrm{~h}$ after immunization. Data are representative of two independent experiments. MHC, major histocompatibility complex.

demonstrated that $\mathrm{CD} 11 \mathrm{~b}^{+}$DCs are massively and transiently recruited to the site of immunization and then to the draining LN. ${ }^{10,24-26}$ Interestingly, the inhibition of their recruitment at the site of immunization suppressed the generation of CD8 T-cell responses, ${ }^{26}$ which strongly supports the conclusion that the antigen is locally taken up by immunostimulatory DCs. Furthermore, it was also documented that DC mobilization to lymph nodes is increased in inflammatory conditions. ${ }^{27}$ We can therefore propose that DCs that have acquired an antigen in immunostimulatory conditions exhibit a phenotype that favors their broad recirculation in lymphoid organs.

Our work demonstrates that antigen-bearing DCs that have captured the antigen in the sublingual mucosa are encountered in the distant lymph nodes and spleen following sublingual immunization (Figures 5-7), which suggests that sublingual DCs enter in the blood circulation to seed distant lymphoid organs. This observation is in line with data showing that mature antigen-bearing DCs derived from tissues were able to traffic to the blood and to recirculate to the spleen and to the bone-marrow to activate T cells. ${ }^{28}$ It was also demonstrated that circulating antigen-bearing $\mathrm{CD} 11 \mathrm{~b}^{+} \mathrm{Sirp} \alpha^{+}$DCs were capable to migrate to the thymus. ${ }^{29}$ These tissue-derived antigenbearing DCs were described to enter in the blood circulation by a mechanism involving either the circulation of DCs from lymphatic circulation to the thoracic duct or a by abluminalluminal transmigration of DCs. ${ }^{30}$ Nevertheless, the molecular mechanisms explaining the entry of antigen-bearing DCs in distant lymphoid organs remains to be investigated.

In conclusion, our data demonstrate that CD8 T-cell responses induced after sublingual immunization in distant mucosal tissues, including the genital mucosa, involve local and distant stimulation of $\mathrm{T}$ cells associated with the recirculation of mucosal antigen-bearing DCs to the distant lymph nodes and spleen.

\section{METHODS}

Mice. C57BL/6 mice and transgenic OT-I mice were from Charles River (L'Arbresle, France). Lang-EGFP (enhanced green fluorescent protein) transgenic mice were from B Malissen's laboratory (CIML, Marseille, France) ${ }^{31}$ Mice were maintained at the animal facilities of the Faculty of Medicine (Nice, France) according to the institutional guidelines.

Surgical removal of lymph nodes. The skin of the neck and the abdomen of anesthetized mice were incised to remove SMLN or/and CLN or inguinal LN. Incisions were closed with interrupted sutures. Two days later, ileo-sacral lymph nodes were removed after incision of the skin and peritoneum. Sublingual immunization was performed 2 weeks later.

Synthesis of CTBOVA conjugates. CT was from List Biologicals Laboratories (Campbell, CA). Recombinant CTB was from Crucell (Stockholm, Sweden). OVA (grade VII, Sigma-Aldrich, St Quentin Fallavier, France) was conjugated to CTB as described earlier. ${ }^{32}$ The resulting CTBOVA conjugate retained both GM1-binding activity and CTB and OVA serological reactivity as determined by GM1-based enzyme-linked immunosorbent assay. ${ }^{33}$ OVA $_{257-264}$ (SIINFEKL) peptide was from Polypeptid Group (Strasbourg, France). Lipopolysaccharide contamination was $<0.12 \mathrm{ng} \mathrm{ml}^{-1}$ (Limulus Amebocyte Lysate Pyrogent Plus, Lonza, Basel, Switzerland).

Immunizations and injections. Anesthetized mice received a 5- $\mu \mathrm{l}$ dose of antigen (CTBOVA $(20 \mu \mathrm{g}$ content in OVA) with CT $(1 \mu \mathrm{g}))$ under the tongue. They were immunized on days 0,14 , and 21 . Mice adoptively transferred with OT-I CD8 naive T cells or not, as well as Lang-EGFP mice received a unique $5 \mu$ l dose of antigen. Organs were collected 3 or 5 days later and specific proliferation analyzed. For Evans blue staining, mice were injected with $5 \mu \mathrm{l}$ of a solution of $10 \%$ Evans blue in phosphate-buffered saline using an insulin syringe and killed at different time points.

In vivo cytotoxic assay. Splenocytes were labeled with CFSE at a concentration of $4 \mu \mathrm{M}\left(\mathrm{CFSE}^{\text {high }}\right)$ or $0.4 \mu \mathrm{M}\left(\mathrm{CFSE}^{\text {low }}\right)$. CFSE ${ }^{\text {high }}$ cells were pulsed with $1 \mu \mathrm{M}$ SIINFEKL peptide. Splenocytes mixed at equal numbers $\left(15 \times 10^{6}\right.$ total cells) were injected intraveinously 7 days after the third immunization. In vivo cytolysis was measured $15 \mathrm{~h}$ later. ${ }^{34}$ CTL detection in the vagina was performed using a modified in vivo 
cytotoxic assay. ${ }^{10}$ Specific cytolysis was calculated using the formula: $\left(1-\left(\left(\right.\right.\right.$ ratio of $\mathrm{CFSE}^{\text {low }} / \mathrm{CFSE}^{\text {high }}$ cells in control mice $) /($ ratio of $\mathrm{CFSE}^{\text {low }} / \mathrm{CFSE}^{\text {high }}$ cells in immunized mice) $\left.) \times 100\right)$.

Adoptive transfer experiments. OT-I peripheral LN were depleted in myeloid cells and activated $\mathrm{T}$ cells using biotinylated Abs (clones RA3-6B2, 2G9, M1/70, RB6-8C5, BM8, and 7D4, respectively) and avidin-coated Dynabeads following the manufacturer's instructions (Dynal Biotech, St Aubin, France). T-cell purity was $>90 \%$. Transgenic T cells were labeled with $10 \mu \mathrm{M}$ CFSE (Molecular Probes, St Aubin, France) and $10 \times 10^{6}$ CFSE-labeled $\mathrm{T}$ cells injected intravenously in recipient mice. Adoptively transferred mice were immunized by sublingual route, and 5 days later, OT-I T-cell proliferation was analyzed in LN by flow cytometry after staining with PE (phycoerythrin)-labeled $\mathrm{H}-2 \mathrm{~K}^{\mathrm{b}} / \mathrm{SIINFEKL}$ Pentamer (ProImmune, Oxford, UK), PE-Cy7-labeled CD8 $\alpha$ (clone 53-6.7), PerCP-labeled CD19 (clone 1D3), and allophycocyanin-labeled CD62L (clone MEL14) (BD Biosciences, Le Pont de Claix, France). Percentages of cells recruited in each division was calculated using the formula $100 \times\left\{1-\left[n_{0} /\left(n_{0}+n_{1} / 2+n_{2} / 4+n_{3} / 8+n_{4} / 16+n_{5} / 32+n_{6} / 64\right)\right]\right\} .{ }^{35}$

Isolation of DCs and ex vivo T-cell proliferation. Spleen DCs, LN DCs and sublingual DCs were purified. ${ }^{10,12,36}$ Sublingual mucosa and tongue were excised and incubated overnight at $4{ }^{\circ} \mathrm{C}$ with Dispase II (1.2 $\mathrm{U} \mathrm{ml}^{-1}$; Roche Diagnostics, Meylan, France) and then digested for $1 \mathrm{~h}$ at $37^{\circ} \mathrm{C}$ with Collagenase/Dispase $\left(2 \mathrm{mg} \mathrm{ml}^{-1}\right.$; Roche Diagnostics) with DNase I $\left(0.1 \mathrm{mg} \mathrm{ml}^{-1}\right)$. LN and sublingual DCs were enriched for DC phenotype analysis. Enriched DC subsets were sorted out on a FACSAria Cell Sorter (BD Biosciences) according to the manufacturer's instructions. DCs used for T-cell proliferation had a purity of $>95 \%$ for CD11c. Sorted DC subsets were co-cultured with $10^{5}$ CFSE-labeled OT-I at different T/DC ratio (between $1 / 1$ and 10/1) in $200 \mu \mathrm{l}$ culture medium at $37^{\circ} \mathrm{C}$ for 5 days.

Flow cytometry. We used Ab against MHCII (clone 2G9), CD24 (clone M1/69 ), CD11b (clone M1/70), CD11c (clone HL3), B220 (clone RA3-6B2), CD45 (clone 30-F11), CD103 (clone M290), and CD205 (clone NLDC-14, Cedarlane, Burlington, Ontario, Canada). Rat IgG2a (clone B39-4) and rat IgG2b (clone A95-1) isotype controls were used. Cell surface $\mathrm{Fc}$ receptors were blocked with purified anti$\mathrm{Fc} \gamma \mathrm{RII} / \mathrm{III} \mathrm{mAb}$ (clone 2.4G2). Analysis was performed on a FACSCanto cytometer with the BD FACSDiva software (BD Biosciences). DC cell sorting from LN or sublingual mucosa was performed on a FACSAria (BD Biosciences).

DC tracking experiments. Sublingual DCs from CD $45.2^{+}$donors were isolated as described before. ${ }^{12} \mathrm{CD} 45.2^{+}$BM-DCs were prepared from $\mathrm{BM}$ precursors and put in culture 8 days with murine rGM-CSF (recombinant granulocyte-macrophage colony-stimulating factor; Peprotech, Neuilly Sur Seine, France) as described. ${ }^{10}$ Sublingual DCs $\left(4 \times 10^{6}\right.$ cells in $\left.10 \mu \mathrm{l}\right)$ or BM-DCs $\left(4 \times 10^{6}\right.$ cells in $\left.10 \mu \mathrm{l}\right)$ were injected in the sublingual mucosa of anesthetized mice, either non-operated mice or mice without SMLN and CLN. Mice were immunized with CT $(2 \mu \mathrm{g})$ as described before. DCs from the SMLN and spleen were analyzed by flow cytometry 24 and $48 \mathrm{~h}$ later. Optiprep low-density fractions from the SMLN and spleen cell suspensions were prepared and stained with antibodies against CD45.1, CD45.2, CD11c, MHCII, B220, and Gr1. Mouse IgG2a isotype control was used to check the specificity of CD45.2 staining.

Immunohistochemistry. Immunohistochemistry of sublingual mucosa was performed as previously. ${ }^{14}$ Sections were incubated with rat CD45 (30-F11) and rat MHCII (2G9) Ab (BD Biosciences) and revealed with biotinylated goat anti-rat IgG and Vectastain ABC kit (Vector Laboratories, Nanterre, France). Sections were stained with 3amino-9-ethylcarbazole $/ \mathrm{H}_{2} \mathrm{O}_{2}$ substrate and counterstained with hematoxylin (DakoCytomation, Les Ulis, France). Isotype control antibodies were used.
Statistics. Results represent means + s.e.m. Statistical significance was assessed using one-way analysis of variance, followed by a Tukey $t$-test. A $P$ value $<0.05$ was considered significant.

SUPPLEMENTARY MATERIAL is linked to the online version of the paper at http://www.nature.com/mi

\section{ACKNOWLEDGEMENTS}

These studies were supported by the Institut National de la Santé et de la Recherche Médicale (France), the Agence Nationale de Recherche sur le SIDA (France), the SIDACTION (France), The European Euroneut-41 Consortium, the Association de Recherche sur le Cancer (ARC), the Canceropole Provence-Alpes-Côte d'Azur (PACA), and the Fondation de l'Avenir (FDA) (France). The authors thank J Casareth for expert technical assistance with cell sorting.

\section{DISCLOSURE}

The authors declared no conflict of interest.

c) 2014 Society for Mucosal Immunology

\section{REFERENCES}

1. Iwasaki, A. Antiviral immune responses in the genital tract: clues for vaccines. Nat. Rev. Immunol. 10, 699-711 (2010).

2. Koup, R.A. \& Douek, D.C. Vaccine design for CD8 T lymphocyte responses. Cold Spring Harb. Perspect. Med. 1, a007252 (2011).

3. Gallichan, W.S. \& Rosenthal, K.L. Long-lived cytotoxic T lymphocyte memory in mucosal tissues after mucosal but not systemic immunization. J. Exp. Med. 184, 1879-1890 (1996).

4. Marks, E., Tam, M.A. \& Lycke, N.Y. The female lower genital tract is a privileged compartment with IL-10 producing dendritic cells and poor Th1 immunity following Chlamydia trachomatis infection.. PLoS Pathog. 6, e1001179 (2010).

5. Bomsel, M. etal. Immunization with HIV-1 gp41 subunit virosomes induces mucosal antibodies protecting nonhuman primates against vaginal SHIV challenges. Immunity 34, 269-280 (2011).

6. Czerkinsky, C., Cuburu, N., Kweon, M.N., Anjuere, F. \& Holmgren, J. Sublingual vaccination. Hum. Vaccination 7, 110-114 (2011).

7. Kweon, M.N. Sublingual mucosa: A new vaccination route for systemic and mucosal immunity. Cytokine 54, 1-5 (2011).

8. Cuburu, N. et al. Sublingual immunization with nonreplicating antigens induces antibody-forming cells and cytotoxic T cells in the female genital tract mucosa and protects against genital papillomavirus infection. J. Immunol. 183, 7851-7859 (2009).

9. Hervouet, C. et al. Sublingual immunization with an HIV subunit vaccine induces antibodies and cytotoxic T cells in the mouse female genital tract. Vaccine 28, 5582-5590 (2010).

10. Luci, C. et al. Dendritic cell-mediated induction of mucosal cytotoxic responses following intravaginal immunization with the nontoxic B subunit of cholera toxin. J. Immunol. 176, 2749-2757 (2006).

11. Lee, H.K. et al. Differential roles of migratory and resident DCs in T cell priming after mucosal or skin HSV-1 infection. J. Exp. Med. 206, 359-370 (2009).

12. Hervouet, C. et al. Langerhans cells prime IL-17-producing $T$ cells and dampen genital cytotoxic responses following mucosal immunization. J. Immunol. 184, 4842-4851 (2010).

13. Sigmundsdottir, H. \& Butcher, E.C. Environmental cues, dendritic cells and the programming of tissue-selective lymphocyte trafficking. Nat. Immunol. 9, 981-987 (2008)

14. Cuburu, N. et al. Sublingual immunization induces broad-based systemic and mucosal immune responses in mice. Vaccine 25, 8598-8610 (2007).

15. Merad, M., Ginhoux, F. \& Collin, M. Origin, homeostasis and function of Langerhans cells and other langerin-expressing dendritic cells. Nat. Rev. Immunol. 8, 935-947 (2008).

16. Van den Broeck, W., Derore, A. \& Simoens, P. Anatomy and nomenclature of murine lymph nodes: descriptive study and nomenclatory standardization in BALB/cAnNCrl mice. J. Immunol. Methods 312, 12-19 (2006).

17. Harrell, M.I., Iritani, B.M. \& Ruddell, A. Lymph node mapping in the mouse. J. Immunol. Methods 332, 170-174 (2008). 
18. Cha, H.R. et al. Mucosa-associated epithelial chemokine/CCL28 expression in the uterus attracts CCR10 + IgA plasma cells following mucosal vaccination via estrogen control. J. Immunol. 187, 3044-3052 (2011).

19. Song, J.H. et al. CCR7-CCL19/CCL21-regulated dendritic cells are responsible for effectiveness of sublingual vaccination. J. Immunol. 182 6851-6860 (2009).

20. Itano, A.A. et al. Distinct dendritic cell populations sequentially present antigen to CD4 $\mathrm{T}$ cells and stimulate different aspects of cell-mediated immunity. Immunity 19, 47-57 (2003).

21. MacKenzie, C.R., Hirama, T., Lee, K.K., Altman, E. \& Young, N.M. Quantitative analysis of bacterial toxin affinity and specificity for glycolipid receptors by surface plasmon resonance. J. Biol. Chem. 272, 5533-5538 (1997).

22. Zhao, X. et al. Vaginal submucosal dendritic cells, but not Langerhans cells, induce protective Th1 responses to herpes simplex virus-2. J. Exp. Med. 197, 153-162 (2003).

23. Wolvers, D.A. et al. Intranasally induced immunological tolerance is determined by characteristics of the draining lymph nodes: studies with OVA and human cartilage gp-39. J. Immunol. 162, 1994-1998 (1999).

24. Anjuere, F. et al. Transcutaneous immunization with cholera toxin B subunit adjuvant suppresses IgE antibody responses via selective induction of Th1 immune responses. J. Immunol. 170, 1586-1592 (2003).

25. Anjuere, F. et al. In vivo adjuvant-induced mobilization and maturation of gut dendritic cells after oral administration of cholera toxin. J. Immunol. 173, 5103-5111 (2004).

26. Le Borgne, M. et al. Dendritic cells rapidly recruited into epithelial tissues via CCR6/CCL20 are responsible for CD8 + T cell crosspriming in vivo. Immunity 24, 191-201 (2006).

27. Angeli, V. et al. B cell-driven lymphangiogenesis in inflamed lymph nodes enhances dendritic cell mobilization. Immunity 24, 203-215 (2006).
28. Cavanagh, L.L. etal. Activation of bone marrow-resident memory Tcells by circulating, antigen-bearing dendritic cells. Nat. Immunol. 6, 1029-1037 (2005).

29. Li, J., Park, J., Foss, D. \& Goldschneider, I. Thymus-homing peripheral dendritic cells constitute two of the three major subsets of dendritic cells in the steady-state thymus. J. Exp. Med. 206, 607-622 (2009).

30. Randolph, G.J., Ochando, J. \& Partida-Sanchez, S. Migration of dendritic cell subsets and their precursors. Annu. Rev. Immunol. 26, 293-316 (2008).

31. Kissenpfennig, A. et al. Dynamics and function of Langerhans cells in vivo: dermal dendritic cells colonize lymph node areas distinct from slower migrating Langerhans cells. Immunity 22, 643-654 (2005).

32. Rask, C. et al. Prolonged oral treatment with low doses of allergen conjugated to cholera toxin B subunit suppresses immunoglobulin E antibody responses in sensitized mice. Clin. Exp. Allergy 30, 1024-1032 (2000).

33. Svennerholm, A., Lange, S. \& Holmgren, J. Correlation between intestinal synthesis of specific immunoglobulin $A$ and protection against experimental cholera in mice. Infect. Immun. 21, 1-6 (1978).

34. Coles, R.M., Mueller, S.N., Heath, W.R., Carbone, F.R. \& Brooks, A.G. Progression of armed CTL from draining lymph node to spleen shortly after localized infection with herpes simplex virus 1. J. Immunol. 168, 834-838 (2002).

35. Lambrecht, B.N., Pauwels, R.A. \& Fazekas De St Groth, B. Induction of rapid T cell activation, division, and recirculation by intratracheal injection of dendritic cells in a TCR transgenic model. J. Immunol. 164, 2937-2946 (2000).

36. Anjuere, F. et al. Definition of dendritic cell subpopulations present in the spleen, Peyer's patches, lymph nodes, and skin of the mouse. Blood 93, 590-598 (1999). 